\title{
Reconstruction of mandibular defects with autogenous bone and decellularized bovine bone grafts with freeze-dried bone marrow stem cell paracrine factors
}

\author{
ANN KAKABADZE ${ }^{1,2}$, KONSTANTINE MARDALEISHVILI ${ }^{1,3}$, GEORGE LOLADZE $^{3}$, LIA KARALASHVILI ${ }^{1,2}$, \\ GOCHA CHUTKERASHVILI $^{2}$, DAVID CHAKHUNASHVILI ${ }^{1}$ and ZURAB KAKABADZE $^{1}$
}

${ }^{1}$ Department of Clinical Anatomy, Tbilisi State Medical University; ${ }^{2}$ Department of Molecular and Translational Medicine, Institute of Medical Research, Ilia State University; ${ }^{3}$ Department of Surgery, Cancer Research Center, 0177 Tbilisi, Georgia

Received July 14, 2016; Accepted November 17, 2016

DOI: $10.3892 / \mathrm{ol} .2017 .5647$

\begin{abstract}
The gold standard following segmental mandibulectomy is vascularized autologous bone graft in the form of the fibula flap. However, in bone reconstruction the use of autogenous bone does not always guarantee a successful outcome. The aim of the present investigation was to develop a novel biologically active bone (BAB) graft, and to use it for the reconstruction of large size defects of the mandible bone following tumor resection. In the first part of the present study, biologically active bone graft was developed by using human freeze-dried bone marrow stem cells (BMSCs) paracrine factors and three-dimensional bone scaffold derived from cancellous bovine bone following decellularization. In the second part of the research, one male and three female patients with primary tumors of the mandible underwent hemimandibulectomy. The mandibular bone defects following tumor resection were reconstructed with autogenous rib grafts in three patients and BAB graft was used in one patient. The graft-host interfaces were covered with decellularized human amnion/chorion membrane graft. All patients were followed-up every five months following the reconstruction of the mandible, with no complications observed. Preliminary clinical investigations demonstrated that a BAB graft containing freeze-dried BMSC paracrine factors may be used for the reconstruction of large mandibular bone defects following tumor resection.
\end{abstract}

Correspondence to: Dr Ann Kakabadze, Department of Clinical Anatomy, Tbilisi State Medical University, 33 Vazha-Pshavela Avenue, 0177 Tbilisi, Georgia

E-mail: anny.kakabadze@gmail.com

Key words: decellularized human amniotic membrane, freeze-dried bone marrow stem cell paracrine factors, three-dimensional bone scaffold, reconstruction of mandibular bone defects, hemimandibulectomy

\section{Introduction}

The gold standard following segmental mandibulectomy is vascularized autologous bone grafts in the form of the fibula flap $(1,2)$. These autografts possess osteoinduction, osteoconduction and osseointegration properties. However, the use of autogenous bone does not necessarily guarantee a successful outcome in bone reconstruction. In cases of large bone defects, there are limits to the amount of cancellous bone grafts that can be harvested from a patient's bones (3). Autogenous bone grafts may also increase the risk of morbidity at the donor site $(4,5)$.

Considering this, there is an interest in allogeneic, xenogeneic and synthetic bone grafts for the reconstruction of bone defects. However, allogeneic and xenogeneic bone grafts have a risk of transmitting various diseases, the potential to develop incompatibility reactions and chronic granulomatous inflammation, and religious restrictions (6-8). The main advantage of synthetic bone grafts is their biocompatibility and bioresorption; however, they are unable to provide full bone regeneration. This is due to insufficient vascularization, weak osteoconductivity, inadequacy of bone formation, lower mechanical resistance and stability of the graft $(9,10)$.

In recent years, biological scaffold materials composed of extracellular matrix (ECM) have been successfully used for the remodeling of a variety of damaged soft tissues and bones, including those in the maxillofacial region (11-16). Tissue-specific ECM serves an important role in promoting tissue regeneration and repair. In order to enhance the osteointegration of bone ECM, bone marrow progenitor cells and platelet rich plasma may be used (17).

Bone marrow stem cells (BMSCs) demonstrate excellent potential for use in cellular therapy and regenerative medicine (18). However, there is currently a growing interest in the process of preservation of various cells by lyophilization $(19,20)$. BMSCs paracrine factors and their role in the process of damaged tissue and organ restoration are increasingly being studied (21-25).

The present study hypothesized that a biologically active bone (BAB) graft may be developed by using freeze-dried BMSC paracrine factors and a three-dimensional bone 
scaffold created from bovine cancellous femoral bones. In the present study, the method for producing BAB grafts and the possibility of applying this product in patients needing reconstruction of large defects of mandibular bone following tumor resection is presented and discussed.

\section{Materials and methods}

Patient information. A total of one male and three female patients (age range, 38-55 years) with primary tumors of the mandible, who underwent surgical treatment between January 2008 and December 2015 in the Cancer Research Center of Tbilisi, Georgia, were enrolled into the present study. All patients signed written informed consent for the present study, which was conducted according to the guidelines of the 1975 Declaration of Helsinki and approved by the Ethics Committee of the Cancer Research Centre in Tbilisi, Georgia.

Patients underwent preoperative orthopantomography, bone scanning, computed tomography (CT) and magnetic resonance imaging. The lesions were biopsied, and the histopathological examination revealed osteoblastoma in three patients and osteoblastic osteosarcoma in one patient. All patients underwent hemimandibulectomy and following tumor resection, mandibular bone defects were reconstructed with autogenous rib grafts in three patients, and BAB graft was used in one patient. The graft-host interfaces were covered with decellularized human amnion/chorion membrane (dHACM) graft.

Fabrication of $B A B$ grafts. Fresh samples of bovine femur bones were collected from a slaughterhouse (Tbilisi, Georgia) 3-4 h subsequent to slaughter. Following bacteriological analysis, the bone was separated from the soft tissue. The femur bones were rinsed in running water for $1 \mathrm{~h}$ and cut with a saw (JG210 Bone Cutting machine; Shandong China Coal Industrial \& Mining Supplies Group Co., Ltd., Shandong, China) into bone fragments of $15 \times 4 \times 2 \mathrm{~cm}$.

Bone fragments were placed in deionized water solution containing 5,000 units/ml heparin (Sigma-Aldrich; EMD Millipore, Billerica, MA, USA) for $24 \mathrm{~h}$ to remove blood components present in the bone. Subsequently, the bone fragments were rinsed with $800 \mathrm{ml} 0.9 \%$ saline solution and frozen at $-80^{\circ} \mathrm{C}$ for at least $12 \mathrm{~h}$ (fragments were fully submerged in the solution). The frozen fragments of bone were thawed at $4^{\circ} \mathrm{C}$ and rinsed with phosphate-buffered saline (PBS; Sigma-Aldrich; EMD Millipore) prior to sequential washes in 0.01, 0.1 and 1\% sodium dodecyl sulfate (SDS; Sigma-Aldrich; EMD Millipore) solution for $72 \mathrm{~h}$. Bone fragments were rinsed with distilled $\mathrm{H}_{2} \mathrm{O}$ for $45 \mathrm{~min}$, followed by $1 \%$ Triton X-100 (Sigma-Aldrich; EMD Millipore) for $2 \mathrm{~h}$ to remove the remaining SDS. Following Triton X-100 treatment, the decellularized bone fragments were rinsed with PBS for $4 \mathrm{~h}$.

The scaffolds were placed in a stirrer and rinsed with a solution containing chloroform and ethanol, initially at a ratio of $2: 1$ for $24 \mathrm{~h}$, then at a ratio of 1:2 for the following $24 \mathrm{~h}$. To remove the remaining chloroform and ethanol, the scaffolds were placed in laboratory grade glass $\left(600-\mathrm{ml} \mathrm{PYREX}^{\mathrm{TM}}\right.$ Griffin Beakers; Thermo Fisher Scientific, Inc., Waltham, MA, USA), then deionized water $(400 \mathrm{ml})$ was added, and the glass was placed on a compact digital mini rotator (\#88880026;
Thermo Fisher Scientific, Inc.), $37^{\circ} \mathrm{C}$, with a gentle shaking speed of $50 \mathrm{rpm}$ for $12 \mathrm{~h}$. Subsequently, the bone fragments were rinsed in fresh deionized water for $2 \mathrm{~h}$.

Decellularized bone fragments (Fig. 1A-D) were placed in a stirrer and rinsed with $4 \%$ sodium hypochlorite for $24 \mathrm{~h}$. To remove the remaining solvent from the deproteinized bone, fragments placed in laboratory grade glass $\left(600-\mathrm{ml} \mathrm{PYREX}^{\mathrm{TM}}\right.$ Griffin Beakers), deionized water $(400 \mathrm{ml})$ was added, and the glass was placed on a compact digital mini rotator at $37^{\circ} \mathrm{C}$, with a gentle shaking speed of $50 \mathrm{rpm}$, and left for $72 \mathrm{~h}$.

dHACM graft was acquired through a previously described decellularization protocol (26). The dHACM grafts that were created by using this method, following lyophilization, were packed in a disposable plastic bag and sterilized with gamma radiation (dose of $15 \mathrm{kGy}$ ). The dHACM grafts were stored aseptically at room temperature until use. Prior to the transplantation, the $\mathrm{dHACM}$ was rehydrated in a $0.9 \%$ saline solution for $30 \mathrm{~min}$.

DNA quantification of BAB grafts. DNA was isolated from the BAB tissue in accordance with manufacturer's protocol using a commercial extraction kit (G-spin Total DNA Extraction Mini kit; iNtRON Biotechnology, Inc., Seongnam, South Korea). The total DNA was determined using a spectrophotometer (NanoDrop 1000; Thermo Fisher Scientific, Inc.) at $260 \mathrm{~nm}$.

Collection of human autologous bone marrow stem cells. A total of 4 days prior to the reconstruction of mandibular defects, between 180-200 $\mathrm{ml}$ of bone marrow was aspirated from the patient's anterior iliac crest under local anesthesia, and placed in sterile tubes containing heparin. The aspirates were diluted 1:2 with PBS. The mononuclear fraction was isolated by density gradient centrifugation at $400 \mathrm{x}$ g for $30 \mathrm{~min}$ at room temperature using Ficoll Paque Plus or Ficoll Paque Premium solution (GE Healthcare Bio-Sciences, Pittsburgh, PA, USA).

Flow cytometry and viability testing. The $0.5 \mathrm{ml}$ final cell product was subjected to a trypan blue dye exclusion test and flow cytometric analysis. The viability test was performed using $0.4 \%$ trypan blue solution (Sigma-Aldrich; EMD Millipore), according to the manufacturer's protocol. For cell immunophenotyping, the cell suspensions were incubated with anti-human cluster of differentiation (CD) 45 FiTC/CD34 PE (dilution, 1:200; \#647821; BD Biosciences, Franklin Lakes, NJ, USA), anti-human CD271 (dilution, 1:100; \#560834; BD Biosciences) and anti-human stromal cell surface marker (STRO-1) antibodies (dilution, 1;100, \#sc-47733; Santa Cruz Biotechnology, Inc., Dallas, TX, USA), diluted in $0.5 \%$ bovine serum albumin/PBS (Sigma-Aldrich; EMD Millipore) buffer, according to the manufacturer's instructions. Flow cytometry analysis was performed on a BD FACSCalibur flow cytometer (BD Biosciences). Mononuclear CD $45^{-/ C D} 34^{-} / \mathrm{CD} 271^{+} / \mathrm{STRO}-1^{+}$cells were defined as bone marrow mesenchymal stem cells, and their percentage and absolute count were recorded. Bone marrow hematopoietic stem cells were determined as the $\mathrm{CD} 45^{+} / \mathrm{CD} 34^{+}$mononuclear cell population.

Cell seeding. The $\mathrm{BAB}$ graft was thoroughly rinsed in sterile PBS for $30 \mathrm{~min}$ and immersed in RPMI-1640 medium 
(Sigma-Aldrich; EMD Millipore) so that only the bottom half of the graft was covered by the media.

In total, $1.2 \times 10^{8}$ mononuclear-enriched cells, suspended in $10 \mathrm{ml}$ saline, were seeded on the top surface of the graft. After $15 \mathrm{~min}$, the grafts were turned over, and the same quantity of cells was seeded on the opposite side. This process was repeated every $15 \mathrm{~min}$ for up to $1 \mathrm{~h}$ to facilitate uniform cell distribution (Fig. 1E and F). Decellularized bovine bone grafts with mononuclear enriched cells were cultivated in a humidified incubator $\left(37^{\circ} \mathrm{C}, 5 \% \mathrm{CO}_{2}\right)$ for 4 days. The differentiation medium was as follows: Dulbecco's modified Eagle's medium-low glucose (Sigma-Aldrich; EMD Millipore) supplemented with $10 \%$ fetal bovine serum (Sigma-Aldrich; EMD Millipore), $1 \mu \mathrm{M}$ dexamethasone (Sigma-Aldrich; EMD Millipore), $50 \mu \mathrm{g} / \mathrm{ml}$ ascorbic acid (Sigma-Aldrich; EMD Millipore), $10 \mathrm{mM}$ sodium $\beta$-glycerophosphate (Sigma-Aldrich; EMD Millipore) and $1 \%$ penicillin/streptomycin (Sigma-Aldrich; EMD Millipore). Subsequently, the bone graft with the seeded mononuclear-enriched cells was lyophilized.

Lyophilization protocol. The process of lyophilization consisted of two stages: Deep freezing of objects and thawing in a vacuum. Following seeding, the BAB graft with BMSCs complex was freeze-dried with a lyophilizer (Heto PowerDry PL6000 Freeze Dryer; Sjia Lab, Shenzhen, China). The temperature of the lyophilizer was set at $-40^{\circ} \mathrm{C}$, and the vacuum was controlled under $10-15 \mathrm{~Pa}$. The thawing procedure lasted for $18-24 \mathrm{~h}$. The chamber was warmed up to $15-20^{\circ} \mathrm{C}$ at a rate of $0.2^{\circ} \mathrm{C} / \mathrm{min}$ and sustained for $6-8 \mathrm{~h}$.

Following lyophilization, the BAB grafts were packed in disposable plastic bags (Wipak Medical, Bomlitz, Germany), following which they were sterilized with gamma-ray doses of $15 \mathrm{kGy}$ and stored in sterile conditions at room temperature until use.

Histology and fluorescence immunohistochemistry of $B A B$ grafts containing freeze-dried BMSCs. Samples of bovine bone were harvested prior to and following decellularization, and were fixed in $10 \%$ neutral buffered formalin, embedded in paraffin, sectioned and stained with hematoxylin and eosin, and Masson's trichrome staining.

Fluorescence immunohistochemistry was performed according to the following methods. For the staining of decellularized bovine bone grafts containing freeze-dried BMSCs with antibodies against CD105/endoglin, bone morphogenetic protein-2 (BMP-2), collagen, type I $\alpha 1$ (I $\alpha 1)$ and fibronectin, formalin-fixed paraffin-embedded tissue sections $5-\mu \mathrm{m}$ thick were cut on a rotary microtome, mounted on charged slides and baked overnight at $50^{\circ} \mathrm{C}$ in an oven. All staining procedures were performed at room temperature.

The slides were deparaffinized and rehydrated in water. Antigen retrieval was performed using steam and proteinase $\mathrm{K}$ digestion methods. Following antigen retrieval, the slides were allowed to cool at room temperature for $20 \mathrm{~min}$, following which the slides were washed three times with PBS for $5 \mathrm{~min}$ each, and then blocked with $3 \% \mathrm{H}_{2} \mathrm{O}_{2}$. Subsequently, the slides were incubated in the primary antibody: CD105/endoglin at 1:100 (\#sc-19793; Santa Cruz Biotechnology, Inc.), BMP-2 at 1:100 (\#sc-6895; Santa Cruz Biotechnology, Inc.) collagen I $\alpha 1$ at 1:100 (\#sc-25974; Santa Cruz Biotechnology, Inc.) and fibronectin at 1:200 (\#sc-8422; Santa Cruz Biotechnology, Inc.) diluted with IHC-Tek Antibody Diluent (IHC World, LLC, Woodstock, MD, USA) for $1 \mathrm{~h}$ at room temperature. The slides were subsequently washed three times in PBS and incubated with a biotinylated secondary antibody at 1:800 dilution (anti-rabbit IgG; \#B7389; Sigma-Aldrich; EMD Millipore) for $30 \mathrm{~min}$. The slides were washed in PBS and incubated with horseradish peroxidase-conjugated streptavidin (\#S2438; Sigma-Aldrich; EMD Millipore) for $30 \mathrm{~min}$, prior to incubation with 3,3'-diaminobenzidine chromogen substrate solution (\#D7304; Sigma-Aldrich; EMD Millipore) for 5-10 min, washing with PBS and counterstaining with Mayer's hematoxylin. Histological slides were analyzed by upright microscope (E100; Nikon Corporation, Tokyo, Japan) and bone fragment tissues by stereoscopic microscope (MBS 9; Lomo, St. Petersburg, Russia). Immunofluorescence staining was analyzed by fluorescence microscope (BH2-RFCA; Olympus Corporation, Tokyo, Japan).

MicroCT. MicroCT scanning was conducted in a $\mu \mathrm{CT} 50$ compact cabinet microCT scanner (SCANCO Medical AG, Bassersdorf, Zurich, Switzerland) using a protocol previously described in detail by Zhu et al (27).

Scanning electron microscopy of $B A B$ grafts containing freeze-dried BMSCs. The BAB grafts were dehydrated by processing with an ethanol solution prior to drying with a tousimis Samdri-780 Critical Point Dryer (Tousimis Research Corporation, Rockville, MD, USA). Following drying, all tissues were sputter coated lightly with gold and imaged on a Hitachi Scanning Electron microscope (Hitachi, Ltd., Tokyo, Japan).

Gene expression analysis of $B A B$ grafts with freeze-dried $B M S C s$. The total RNA from the bone tissue was purified using a miRNeasy mini kit, according to the manufacturer's instructions (Qiagen GmbH, Hilden, Germany). cDNA was synthesized using the iScript cDNA synthesis kit (Bio-Rad Laboratories, Inc., Hercules, CA, USA). Quantitative polymerase chain reaction (qPCR) was performed using iTaq Universal SYBR Green supermix (Bio-Rad Laboratories, Inc.) and a 7500 Fast Real-Time PCR system (Thermo Fisher Scientific, Inc.). Thermal cycling conditions were as follows: $15 \mathrm{~min}$ of denaturation at $95^{\circ} \mathrm{C}$, followed by 40 cycles of denaturation for $15 \mathrm{sec}$ at $95^{\circ} \mathrm{C}$, annealing for $30 \mathrm{sec}$ at $60^{\circ} \mathrm{C}$ and elongation for $20 \mathrm{sec}$ at $72^{\circ} \mathrm{C}$. The $18 \mathrm{~S}$ rRNA was used as an internal control for gene expression normalization, which is considered to be the most reliable reference gene for normalization of qPCR data (28).

The polymerase chain reaction (PCR) amplification was performed using the following primer sets: BMP7 forward, 5'ACAGACCAAGCACCTCTCCT-3' and reverse, 5'-CGG TGTGCTCAGGTTTCTAA-3'; BMP8a forward, 5'-ATTATG GTGGTCAGGGCATT-3' and reverse, 5'-GCACCGTTATAC CTGGCTCT-3'; epidermal growth factor (EGF) forward, 5'-ACTGGGAGCAGACAGAAGGT-3' and reverse, 5'-ATT AGCCGTGGAGACAGGAG-3'; vascular endothelial growth factor (VEGF) forward, 5'-AGATTCTGCAAGAGCACC CT-3' and reverse, 5'-CCTAGGCTCCTCAGAAGTGG-3'; 

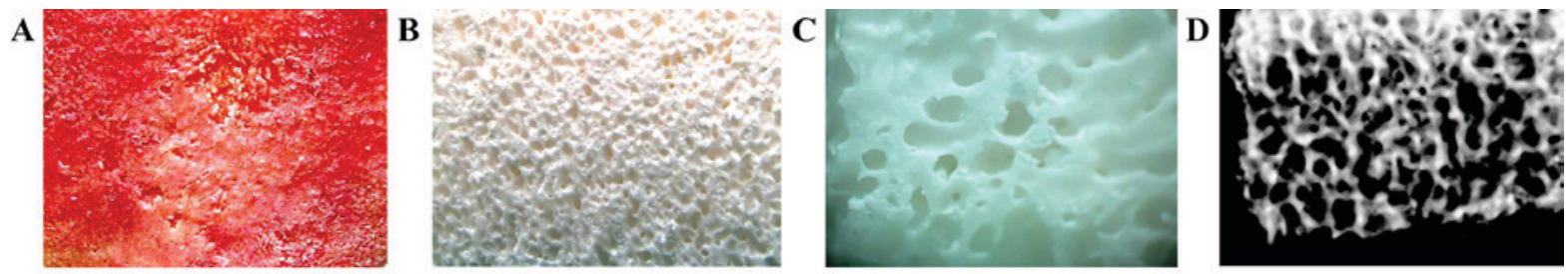

$\mathbf{E}$
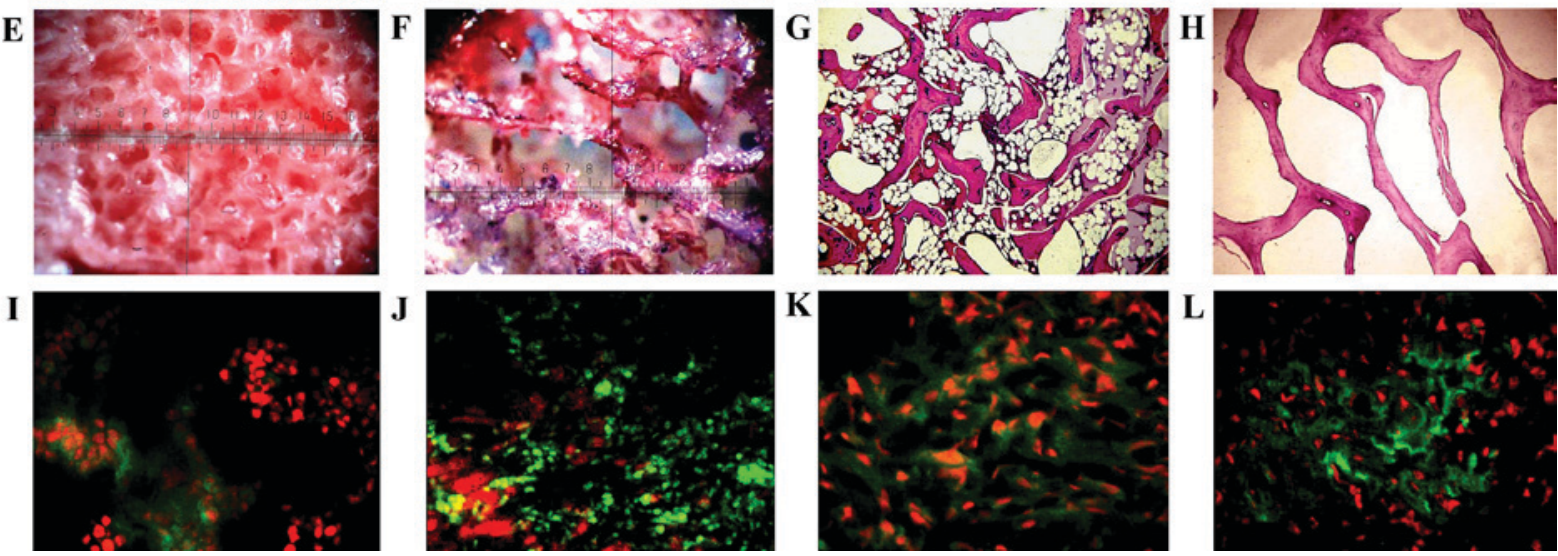

Figure 1. Bovine bone prior to and following decellularization, lyophilization and seeding with human freeze-dried bone marrow stem cells. (A) Stereoscopic microscope image of native bovine trabecular bone (x16 magnification), (B) decellularized bovine bone graft (x16 magnification) and (C) porous frontal surface of the bone graft (x32 magnification). (D) Micro computed tomography image of decellularized bone tissue (scale bar, $1 \mathrm{~mm}$ ). (E) Stereoscopic microscope image of rear surface of decellularized and lyophilized bovine bone graft placed in RPMI-1640 medium (x32 magnification) and (F) bone marrow stem cells seeded on the surface of the decellularized bone graft (x56 magnification). (G) Native and (H) decellularized bovine bone graft stained with hematoxylin and eosin (magnification, x400). (I) Cluster of differentiation 105/endoglin (x100 magnification), (J) bone morphogenetic protein-2, (x100 magnification) (K) collagen type I $\alpha 1$ (x100 magnification) and (L) fibronectin (x100 magnification) expression in biologically active bone grafts with freeze-dried bone marrow stem cells.

fibroblast growth factor forward, 5'-ACCGGTACCTGGCTA TGAAG-3' and reverse, 5'-GTGCCACATACCAACTGG AG-3'; osteopontin forward, 5'-TCCAGGAGTTTCCCTGTT TC-3' and reverse, 5'-TGACCTTGATAGCCTCATCG-3'; osteocalcin forward, 5'-CTGCATTCTGCCTCTCTGAC-3' and reverse, 5'-CCGGAGTCTATTCACCACCT-3'; bone sialoprotein forward, 5'-GAGACAACGGAGAAGAAGCC-3' and reverse, 5'-CCATAACTGGTCAGCTCCCT-3'; 18S rRNA forward, 5'-TAAAGGAATTGACGGAAGGG-3' and reverse, 5'-CTGTCAATCCTGTCCGTGTC-3' (29).

\section{Results}

Characterization of $B A B$ graft. Following decellularization, cancellous bone fragments acquired from bovine femur bones are a light yellow color; they have a desired three-dimensional porous structure and may be repopulated by host bone-forming cells (30). The DNA content of the fresh samples of bovine femur bones prior to treatment was $482 \mu \mathrm{g} / \mathrm{ml}$. Following the decellularization procedure, the residual DNA content was $<1.4 \%$. Histological investigation indicated the presence of osteocytes in the native tissue, whereas in the decellularized tissues, the presence of cellular material was not observed (Fig. 1G and H). Following decellularization, the mesh of collagen fibers had retained their structure and was similar to natural bone. However, the collagen arrangements were disturbed, with gaps between the collagen fibers.

A cross-section of the BAB graft following cell seeding indicated the presence of the cells at depth in the scaffolds, in addition to along the sides of the scaffolds. However, there were separate areas in the central regions of the BAB graft where the cells were not homogenously distributed. Immunohistochemical investigation demonstrated the presence of CD105/endoglin, BMP-2, collagen I $\alpha 1$ and fibronectin in the BAB grafts containing freeze-dried BMSCs (Fig. 1I-L).

Low magnification scanning electron micrographs demonstrated decellularized bovine bone, observed as a mesh of collagen fibers that were intact and which were similar to the structure of natural bone. Freeze-dried BMSCs (Fig. 2A-D) that were seeded on the BAB graft were scattered between the collagen fibers (Fig. 2E-H), and their arrangement was compact and orderly.

Gene expression analysis demonstrated that the BAB grafts containing freeze-dried BMSCs expressed a large number of varying growth factors, in particular osteocalcin and osteopontin, which may enhance the osteogenic process (Fig. 3).

Clinical data. Out of three female patients that were enrolled in the present study, two underwent right hemimandibulectomy and one underwent left hemimandibulectomy. The mandibular resections were all lateralized and none crossed the symphysis menti. Surgical defects were restored with autogenous rib grafts (Fig. 4A and B). Following the stabilization of the host mandible bone and autologous rib grafts with a titanium plate, the $\mathrm{dHACM}$ graft was placed around the defect (Fig. 4C and D). The dimensions of the dHACM graft were $10 \times 4 \mathrm{~cm}$, and placement ensured that a $2 \mathrm{~cm}$ portion of the graft overlapped with the intact portions beyond the proximal and distal defect interfaces. The dHACM graft was then secured in place (stretched in all directions) with a $2 / 0$ vicryl suture with measures to assure that no vessels or muscles were included. 

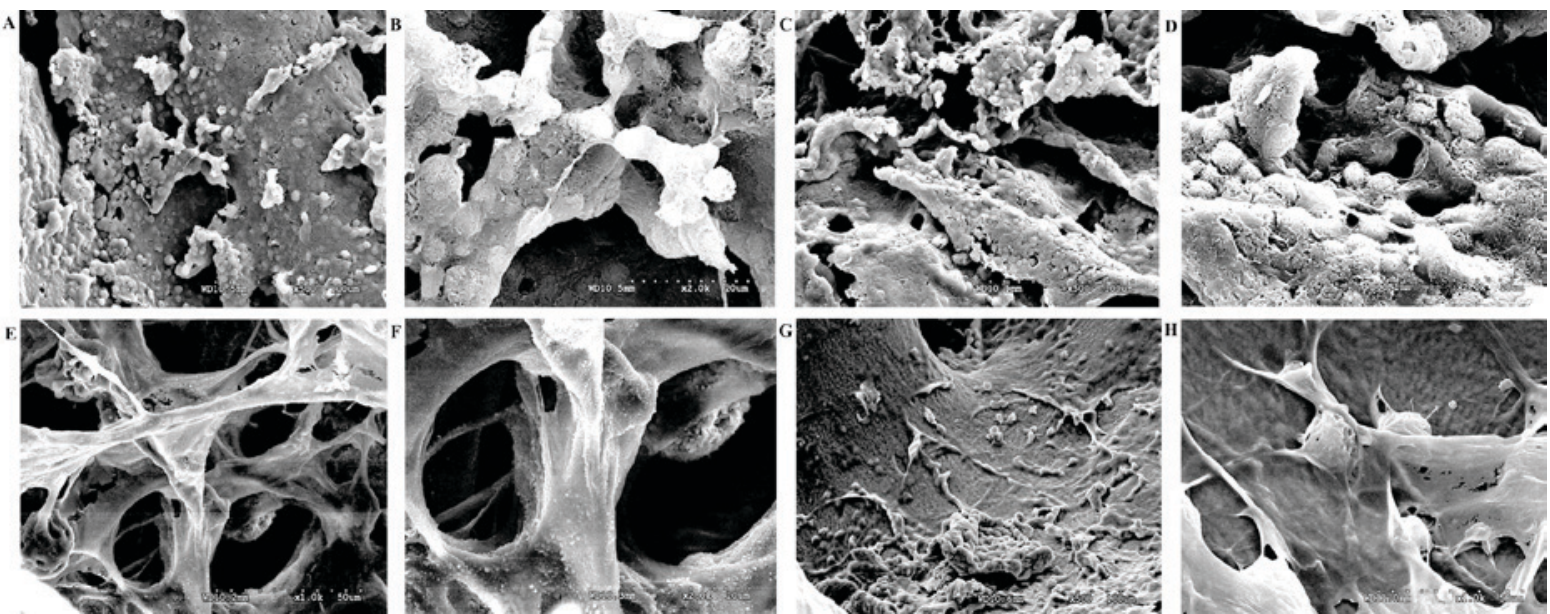

Figure 2. Scanning electron microscopy of bone graft and freeze-dried human bone marrow stem cells. (A and B) Human bone marrow stem cell prior to (magnification, x500 and x2,000, respectively) and (C and D) following freeze-drying (magnification, x500 and x2,000, respectively). (E and F) Scanning electron micrograph of the bone graft (magnification x1,000 and x2,000, respectively). (G and $\mathrm{H}$ ) Scanning electron micrograph of bone marrow stem cells seeded on the decellularized bone graft (magnification, x500 and x1,000, respectively).

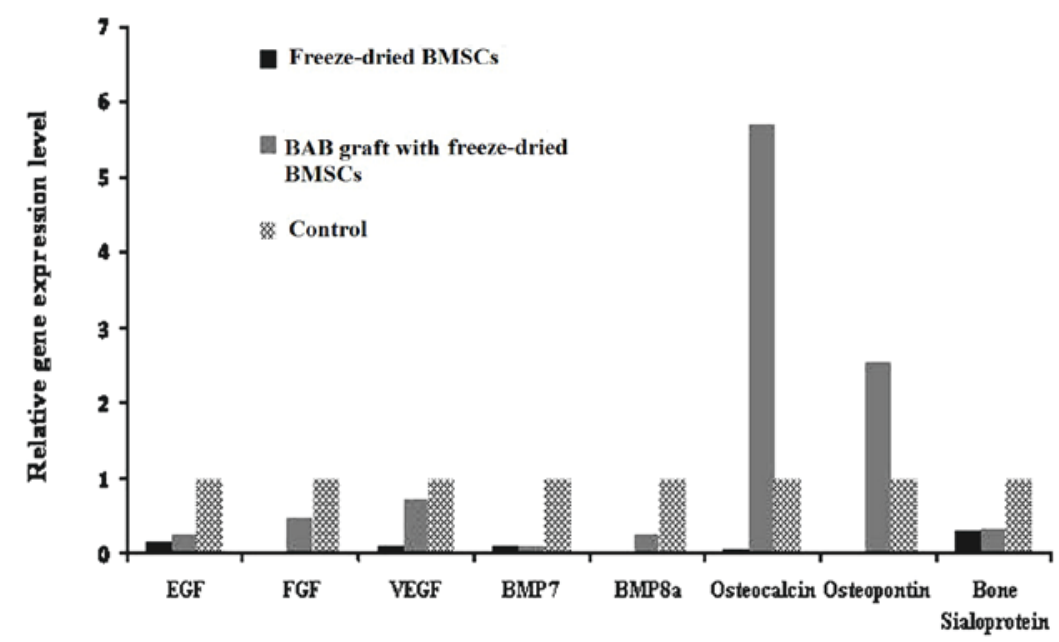

Figure 3. Relative gene expression levels in isolated freeze-dried BMSCs and decellularized bovine bone grafts seeded with freeze-dried BMSCs. Gene expression analysis demonstrated that the BAB grafts containing freeze-dried BMSCs expressed a large number of varying growth factors, in particular osteocalcin and osteopontin. BMSCs, bone marrow stem cells; BAB, biologically active bone; EGF, epidermal growth factor; FGF, fibroblast growth factor; VEGF, vascular endothelial growth factor; BMP, bone morphogenetic protein.

In one male patient, aged 38 years, the solid tumor involved the whole of the left mandible, including the body and ramus. The lesion was biopsied which indicated osteoblastic osteosarcoma. The left hemimandible was removed en bloc with the tumor (Fig. 4E).

Therefore, the initial plan to bridge the bony gap created with a titanium plate was not possible and the wound was closed primarily without reconstruction. Following 5 years of follow-up, complete remission was observed in this patient. For the reconstruction of the mandible bone defect, the BAB graft containing freeze-dried BMSC paracrine factors was selected (Fig. 4F). The titanium plate was used to stabilize the host bone (Fig. 4G and $\mathrm{H}$ ), and additionally a dHACM wrap was used to cover the defect (Fig. 4I). The thoracodorsal flap on the vascular pedicle was used for the complete closure of the soft tissue without tension (Fig. 4J-M). The patient was followed-up every five months following the reconstruction of the mandible, and no complications were observed (Fig. $4 \mathrm{~N}$ and O). A total of 5 months subsequent to mandible bone reconstruction, $\mathrm{x}$-ray imaging demonstrated bone volume maintenance (Fig. 4P).

\section{Discussion}

Bones exhibit an excellent ability for healing via the natural mechanisms of bone repair (4). However, the healing process in patients following bone tumor resection may be slow or inadequate (31).

Previous investigations showed that autogenous rib graft demonstrates a positive effect on the reconstruction of mandibular bone defects, as the autogenous grafts activate the mechanisms of bone formation, including osteoconduction, osteinduction and osteogenesis (32-35).

However, in cases with large defects of the mandible, reconstruction with autogenous bone grafts represents a great 

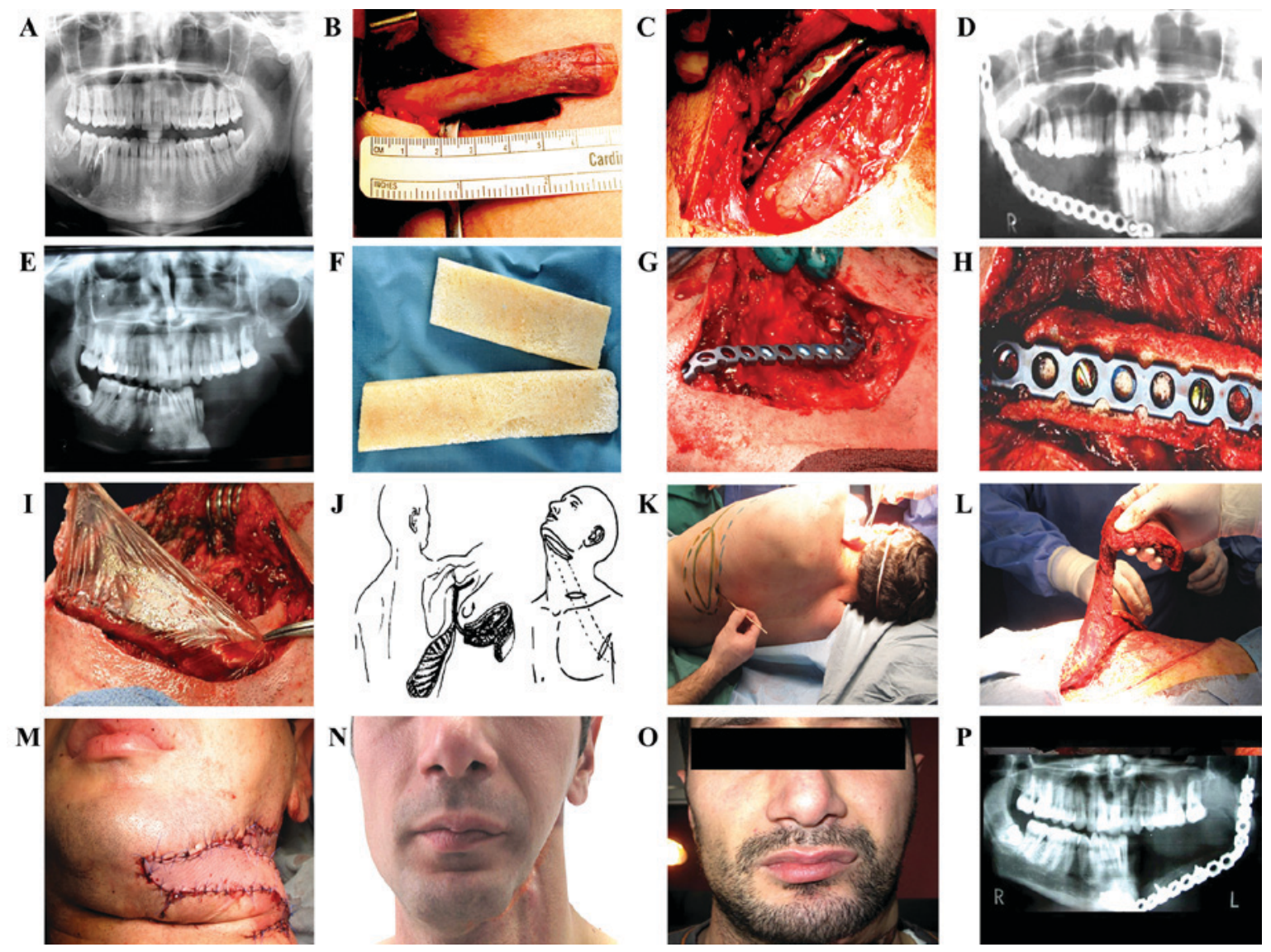

Figure 4. Reconstruction of mandibular bone defects with autogenous rib grafts and decellularized bovine bone grafts seeded with freeze-dried bone marrow stem cell paracrine factors. (A) X-ray of the patient diagnosed with osteoblastoma in the right portion of the mandibular body. (B) Reconstruction of the mandible with an autogenous VI rib graft. (C) Autogenous rib graft, titanium plate and host mandibular bone covered with a decellularized human amnion/chorion membrane graft. (D) Postoperative X-ray after five months of follow-up. (E) Postoperative X-ray following left hemimandibulectomy in a patient with osteoblastic osteosarcoma. (F-H) Reconstruction of the mandibular defect with a titanium plate and biologically active bone graft seeded with freeze-dried bone marrow stem cell paracrine factors. (I) Decellularized human amnion/chorion membrane graft used to cover the defect. (J-M) Thoracodorsal flap on the vascular pedicle was used for complete closure of the soft tissue without tension. ( $\mathrm{N}$ and $\mathrm{O}$ ) Pre- and postoperative appearance following mandibular reconstruction with the preserved contour of the mandible and face. (P) X-ray image five months subsequent to mandible bone defect reconstruction demonstrating bone volume maintenance.

challenge, as the structure and large size of the graft slows the revascularization process (36). A previous study reported non-vascularized graft failure in $17 \%$ of cases where the defect size was $6 \mathrm{~cm}$, and in $75 \%$ of cases where the defect was $\geq 12 \mathrm{~cm}$ (37).

Decellularized bone scaffolds have been considered as an alternative to autogenous grafts (38-40). The main drawback for these materials is that they have osteoinductive and osteoconductive characteristics; however, they lack the osteogenic properties that are present in autologous grafts (41). Following the seeding of freeze-dried BMSC paracrine factors on BAB grafts, which possess osteoinductive and osteoconductive features, these grafts additionally exhibited osteogenic properties. The complete absence or the presence of only minimal DNA following decellularization means $\mathrm{BAB}$ grafts are biocompatible and do not induce antigen-antibody reactions $(41,42)$.

Once implanted or injected, the BMSCs at the site of the lesion differentiate into several cell types $(43,44)$. However, the mechanism of differentiation currently remains to be elucidated. Recently, BMSC paracrine factors and their role in the restoration of damaged tissues and organs have received increased interest (45-47).
BMSC paracrine factors stimulate tissue regeneration via effects on homing, immunosuppression, differentiation, angiogenesis, stimulation of endogenous cells and potential regulation of specific metabolic signaling pathways (25). Following freeze-drying, BMSCs have been observed to retain $>80 \%$ of paracrine factors, including VEGF-1, insulin-like growth factor 1, EGF, hepatocyte growth factor, keratinocyte growth factor, angiopoietin-1, stromal cell-derived factor-1, monocyte chemoattractant protein-1 and erythropoietin $(24,48-50)$.

In order to prevent the invasion of fibrous tissue between the autologous bone or BAB graft, and the host mandible bone, $\mathrm{dHACM}$ has been used as a barrier membrane. In examined cases in the present study, it was observed that using dHACM for the reconstruction of mandibular bone defects enhanced osseointegration and provided solid protection against fibrous tissue invasion between the bone graft and host mandible bone. Similar results have also been previously reported (51-55).

In a previous study (26), the present authors demonstrated that the dHACM contained type III collagen, glycoproteins and numerous growth factors, including epidermal growth factor, basic fibroblast growth factor, keratinocyte growth factor, VEGF, TGF $\alpha$, TGF $\beta$, PDGF, hepatocyte growth 
factor and nerve growth factor. Following the decellularization of the dHACM, the majority of the growth factors and cytokines, and the structural and mechanical properties were preserved. In addition, $\mathrm{dHACM}$ is easy to prepare and handle, and by its use, fibrous tissue invasion can be prevented $(51,56)$.

Micromovements between the host mandibular bone and any type of donor bone graft prevent bone formation, due to fibrous tissue invasion $(52,53)$. Non-rigidly fixed defects with no membrane showed ingrowths of fibroblasts and fibrous nonunions (54-56).

In conclusion, BAB grafts seeded with freeze-dried BMSC paracrine factors hold great promise for the future of mandible defect reconstruction following tumor resection. As a result, this type of composite graft should be able negate the need for harvesting donor bone. Preliminary clinical investigations indicated that BAB grafts containing freeze-dried BMSCs paracrine factors may be used for the reconstruction of large mandibular bone defects following tumor resection. The dHACM graft efficiently induces the bone formation, and protects against fibrous tissue invasion between the bone grafts and host bone.

\section{References}

1. Chim H, Salgado CJ, Mardini S and Chen HC: Reconstruction of mandibular defects. Semin Plast Surg 24: 188-197, 2010.

2. Yap YL,Lim J, Ong WC, Yeo M, Lee H and Lim TC: Stabilization of mobile mandibular segments in mandibular reconstruction: Use of spanning reconstruction plate. Craniomaxillofac Trauma Reconstr 5: 123-126, 2012.

3. Clokie CM and Sándor GK: Reconstruction of 10 major mandibular defects using bioimplants containing BMP-7. J Can Dent Assoc 4: 67-72, 2008.

4. Frohlich M, Grayson WL, Wan LQ, Marolt D, Drobnic M and Vunjak-Novakovic G: Tissue engineered bone grafts: Biological requirements, tissue culture and clinical relevance. Curr Stem Cell Res Ther 3: 254-264, 2008.

5. Finkemeier CG: Bone-grafting and bone-graft substitutes J Bone Joint Surg Am 84-A: 454-464, 2002.

6. Kaláb M, Karkoška J, Kamínek M and Šantavý P: Successful three-year outcome in a patient with allogenous sternal bone graft in the treatment of massive post-sternotomy defects. Int J Surg Case Rep 7C: 6-9, 2014.

7. Schleicher I, Lips KS, Sommer U, Schappat I, Martin AP, Szalay G and Schnettler R: Allogenous bone with collagen for repair of deep osteochondral defects. J Surg Res 185: 667-675, 2013.

8. Gomes KU, Carlini JL, Biron C, Rapoport A and Dedivitis RA: Use of allogeneic bone graft in maxillary reconstruction for installation of dental implants. J Oral Maxillofac Surg 66 2335-2358, 2008

9. Oryan A, Alidadi S, Moshiri A and Maffulli N: Bone regenerative medicine: Classic options, novel strategies and future directions J Orthop Surg Res 9: 18, 2014

10. Friesenbichler J, Maurer-Ertl W, Sadoghi P, Pirker-Fruehauf U, Bodo $\mathrm{K}$ and Leithner A: Adverse reactions of artificial bone graft substitutes: Lessons learned from using tricalcium phosphate geneXR. Clin Orthop Relat Res 472: 976-682, 2014.

11. Han F, Dong Y, Su Z, Yin R, Song A and Li S: Preparation, characteristics and assessment of a novel gelatin-chitosan sponge scaffold as skin tissue engineering material. Int J Pharm 476 : 124-133, 2014

12. Noth U, Schupp K, Heymer A, Kall S, Jakob F, Schütze N, Baumann B, Barthel T, Eulert J and Hendrich C: Anterior cruciate ligament constructs fabricated from human mesenchymal stem cells in a collagen type I hydrogel. Cytotherapy 7 : 447-455, 2005

13. Mohan N, Nair PD and Tabata Y: A 3D biodegradable protein based matrix for cartilage tissue engineering and stem cell differentiation to cartilage. J Mater Sci Mater Med 20 (Suppl 1) S49-S60, 2009.
14. Fröhlich M, Grayson WL, Marolt D, Gimble JM, Kregar-Velikonja N and Vunjak-Novakovic G: Bone grafts engineered from human adipose-derived stem cells in perfusion bioreactor culture. Tissue Eng Part A 16: 179-189, 2010.

15. Liu Y, Ahmad S, Shu XZ, Sanders RK, Kopesec SA and Prestwich GD: Accelerated repair of cortical bone defects using a synthetic extracellular matrix to deliver human demineralized bone matrix. J Orthop Res 24: 1454-1462, 2006.

16. Kinoshita Y and Maeda H: Recent developments of functional scaffolds for craniomaxillofacial bone tissue engineering applications. ScientificWorldJournal 2013: 863157, 2013.

17. Zhang SZ, Qian H, Wang Z, Fan JL, Zhou Q, Chen GM, Li R, Fu S and Sun J: Preliminary study on the freeze-drying of human bone marrow-derived mesenchymal stem cells. J Zhejiang Univ Sci B 11: 889-894, 2010.

18. Fisher JN, Peretti GM and Scotti C: Stem cells for bone regeneration: From cell-based therapies to decellularised engineered extracellular matrices. Stem Cells Int 2016: 9352598, 2016.

19. Ward MA, Kaneko T, Kusakabe H, Biggers JD, Whittingham DG and Yanagimachi R: Long-term preservation of mouse spermatozoa after freeze-drying and freezing without cryoprotection. Biol Reprod 69: 2100-2108, 2003.

20. Natan D, Nagler A and Arav A: Freeze-drying of mononuclear cells derived from umbilical cord blood followed by colony formation. PLoS One 4: e5240, 2009.

21. Linero I and Chaparro O: Paracrine effect of mesenchymal stem cells derived from human adipose tissue in bone regeneration. PLoS One 9: e107001, 2014

22. Nowotny J, Farack J, Vater C, Johnsen M, Gelinsky M, Tonn T and Kasten P: Translation of cell therapy into clinical practice: Validation of an application procedure for bone marrow progenitor cells and platelet rich plasma. J Appl Biomater Funct Mater 14: e1-e8, 2015.

23. Liang X, Ding Y, Zhang Y, Tse HF and Lian Q: Paracrine mechanisms of mesenchymal stem cell-based therapy: Current status and perspectives. Cell Transplant 23: 1045-1059, 2014.

24. Peng Y, Xuan M, Zou J, Liu H, Zhuo Z, Wan Y and Cheng B: Freeze-dried rat bone marrow mesenchymal stem cell paracrine factors: A simplified novel material for skin wound therapy. Tissue Eng Part A 21: 1036-1046, 2015.

25. Burdon TJ, Paul A, Noiseux N, Prakash S and Shum-Tim D Bone marrow stem cell derived paracrine factors for regenerative medicine: Current perspectives and therapeutic potential. Bone Marrow Res 2011: 207326, 2011

26. Kakabadze Z, Mardaleishvili K, Loladze G, Javakhishvili I, Chakhunashvili K, Karalashvili L, Sukhitashvili N, Chutkerashvili G, Kakabadze A and Chakhunashvili D: Clinical application of decellularized and lyophilized human amnion/chorion membrane grafts for closing post-laryngectomy pharyngocutaneous fistulas. J Surg Oncol 113: 538-543, 2016.

27. Zhu S, Zhu Q, Liu X, Yang W, Jian Y, Zhou X, He B, Gu L, Yan L, Lin T, et al: Three-dimensional reconstruction of the microstructure of human acellular nerve allograft. Sci Rep 6: 30694, 2016.

28. Kim BR, Nam HY, Kim SU, Kim SI and Chang YJ: Normalization of reverse transcription quantitative-PCR with housekeeping genes in rice. Biotechnol Lett 25: 1869-1872, 2003.

29. Livak KJ and Schmittgen TD: Analysis of relative gene expression data using real-time quantitative PCR and the 2(-Delta Delta C(T)) Method. Methods 25: 402-88, 2001

30. Lawrence BJ and Madihally SV: Cell colonization in degradable 3D porous matrices. Cell Adh Migr 2: 9-16, 2008.

31. Sterling JA and Guelcher SA: Biomaterial scaffolds for treating osteoporotic bone. Curr Osteoporos Rep 12: 48-54, 2014.

32. Zou W and Chen X: Osteogenesis and ototoxicity of a novel preparation of autogenous bone cement: Implications for mastoid obliteration. Otolaryngol Head Neck Surg 151: 1020-1027, 2014.

33. Tera Tde M, Prado RF, De Marco AC, Santamaria MP and Jardini MA: The RANK/ RANKL/ OPG interaction in the repair of autogenous bone grafts in female rats with estrogen deficiency. Braz Oral Res 28: S1806-83242014000100261, 2014.

34. Bastos AS, Spin-Neto R, Conte-Neto N, Galina K, Boeck-Neto RJ, Marcantonio C, Marcantonio E and Marcantonio E Jr: Calvarial autogenous bone graft for maxillary ridge and sinus reconstruction for rehabilitation with dental implants. J Oral Implantol 40: 469-478, 2014

35. Al-Nawas B and Schiegnitz E: Augmentation procedures using bone substitute materials or autogenous bone-a systematic review and meta-analysis. Eur J Oral Implantol 7 (Suppl 2): S219-S234, 2014. 
36. Koerdt S, Siebers J, Bloch W, Ristow O, Kuebler AC and Reuther T: Immunohistochemial study on the expression of von Willebrand factor (vWF) after onlay autogenous iliac grafts for lateral alveolar ridge augmentation. Head Face Med 9: 40, 2013.

37. Pogrel MA, Podlesh S, Anthony JP and Alexander J: A comparison of vascularized and nonvascularized bone grafts for reconstruction of mandibular continuity defects. J Oral Maxillofac Surg 55: 1200-1206, 1997.

38. Pennington EC, Dionigi B, Gray FL, Ahmed A, Brazzo J, Dolinko A, Calderon N, Darrah T, Zurakowski D, Nazarian A, et al: Limb reconstruction with decellularized, non-demineralized bone in a young leporine model. Biomed Mater 10: 015021, 2015.

39. Gawlitta D, Benders KE, Visser J, van der Sar AS, Kempen DH, Theyse LF, Malda J and Dhert WJ: Decellularized cartilage-derived matrix as substrate for endochondral bone regeneration. Tissue Eng Part A 21: 694-703, 2015.

40. Hoffman MD, Van Hove AH and Benoit DS: Degradable hydrogels for spatiotemporal control of mesenchymal stem cells localized at decellularized bone allografts. Acta Biomater 10: 3431-3441, 2014.

41. Gardin C, Ricci S, Ferroni L, Guazzo R, Sbricoli L, De Benedictis G, Finotti L, Isola M, Bressan E and Zavan B: Decellularization and delipidation protocols of bovine bone and pericardium for bone grafting and guided bone regeneration procedures. PLoS One 10: e0132344, 2015.

42. Quan TM, Vu DN, My NTN and Ha TLB: Decellularization of xenogenic bone grafts for potential use as tissue engineering scaffolds. International Journal of Life Science and Medical Research Aug 4: 38-45, 2014.

43. Chatterjea A, Meijer G, van Blitterswijk C and de Boer J: Clinical application of human mesenchymal stromal cells for bone tissue engineering. Stem Cells Int 215625, 2010.

44. Salem HK and Thiemermann C: Mesenchymal stromal cells: Current understanding and clinical status. Stem Cells 28: 585-596, 2010.

45. Chen Y, Shao JZ, Xiang LX, Dong XJ and Zhang GR: Mesenchymal stem cells: A promising candidate in regenerative medicine. Int J Biochem Cell Biol 40: 815-820, 2008.

46. Meirelles Lda S, Fontes AM, Covas DT and Caplan AI: Mechanisms involved in the therapeutic properties of mesenchymal stem cells. Cytokine Growth Factor Rev 20: 419-427, 2009.
47. Hocking AM and Gibran NS: Mesenchymal stem cells: Paracrine signaling and differentiation during cutaneous wound repair. Exp Cell Res 316: 2213-2219, 2010.

48. Kinnaird T, Stabile E, Burnett MS, Lee CW, Barr S, Fuchs S and Epstein SE: Marrow-derived stromal cells express genes encoding a broad spectrum of arteriogenic cytokines and promote in vitro and in vivo arteriogenesis through paracrine mechanisms. Circ Res 94: 678-685, 2004.

49. Rehman J, Traktuev D, Li J, Merfeld-Clauss S, Temm-Grove CJ, Bovenkerk JE, Pell CL, Johnstone BH, Considine RV and March KL: Secretion of angiogenic and antiapoptotic factors by human adipose stromal cells. Circulation 109: 1292-1298, 2004.

50. Takahashi M, Li TS, Suzuki R, Kobayashi T, Ito H, Ikeda Y, Matsuzaki M and Hamano K: Cytokines produced by bone marrow cells can contribute to functional improvement of the infarcted heart by protecting cardiomyocytes from ischemic injury. Am J Physiol Heart Circ Physiol 291: H886, 2006.

51. Li W, Ma G, Brazile B, Li N, Dai W, Butler JR, Claude AA, Wertheim JA, Liao J and Wang B: Investigating the potential of amnion-based scaffolds as a barrier membrane for guided bone regeneration. Langmuir 31: 8642-8653, 2015.

52. Ducheyne P, De Meester P and Aernoudt E: Influence of a functional dynamic loading on bone ingrowth into surface pores of orthopedic implants. J Biomed Mater Res 11: 811-838, 1977.

53. Heck D, Nakajima I, Kelly P and Chao E: The effect of load alteration on the biological and biomechanical performance of a titanium fiber-metal segmental prosthesis. J Bone Joint Surg Am 68: 118-126, 1986.

54. Gutta R, Baker RA, Bartolucci AA and Louis PJ: Barrier membranes used for ridge augmentation: Is there an optimal pore size? J Oral Maxillofac Surg 67: 1218-1225, 2009.

55. Amano Y, Ota M, Sekiguchi K, Shibukawa Y and Yamada S: Evaluation of a poly-l-lactic acid membrane and membrane fixing pin for guided tissue regeneration on bone defects in dogs. Oral Surg Oral Med Oral Pathol Oral Radiol Endod 97: 155-163, 2004.

56. von Arx T, Cochran DL, Hermann JS, Schenk RK and Buser D: Lateral ridge augmentation using different bone fillers and barrier membrane application. A histologic and histomorphometric pilot study in the canine mandible. Clin Oral Implants Res 12: 260-269, 2001. 